\title{
STABILITY OF CUBIPOD ARMOURED ROUNDHEADS IN SHORT-CRESTED WAVES. A COMPARISON BETWEEN CUBIPOD AND CUBE ARMOUR STABILITY
}

\author{
Hans F. Burcharth ${ }^{1}$, Thomas Lykke Andersen ${ }^{1}$ and Josep R.Medina ${ }^{2}$
}

\begin{abstract}
The paper presents a comparison of the stability of concrete cube armour and Cubipod armour in a breakwater roundhead with slope 1:1.5, exposed to both 2-D (long-crested) and 3-D (short-crested) waves. The model tests were performed at the Hydraulics and Coastal Engineering Laboratory at Aalborg University, Denmark. The model tests showed that Cubipod armour is more stable than cube armour when exposed to longer waves (steepness approx. 0.025 ) and has equal stability to cubes in shorter waves. The Cubipod armour layer contained due to its high porosity approximately $6-17 \%$ less concrete than the cube armour layer. Therefore, it was concluded that per used volume of concrete the Cubipods perform better than the cubes.
\end{abstract}

Keywords: breakwaters; concrete armour; Cubipod; roundheads; short-crested waves

\section{INTRODUCTION}

The roundhead is generally the most exposed part of the breakwater. Moreover, in case of rubble mound structures the needed armour size is larger than in the adjacent trunk. Typically units of almost double mass are needed in the roundhead if high density stones or concrete are not used in the head. The Cubipod as shown in Fig. 1 is a relatively new development, see Gómez-Martin and Medina (2008) for details.

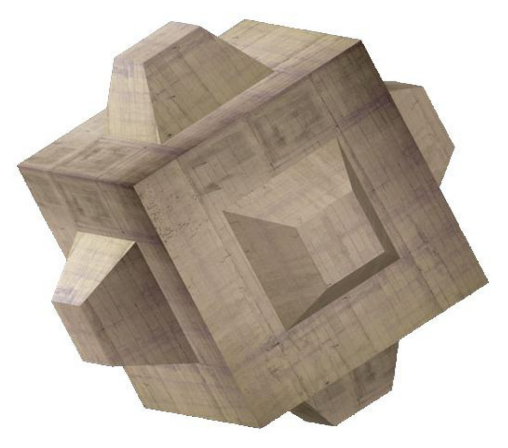

Figure 1. Cubipod armour unit.

The Cubipod is similar to a cube except that it features protrusions on each face to prevent locally strongly varying packing density as well as to increase the friction against the filter layer.

A comparison of the stability of Cubipod and cube armoured roundheads has been performed at the Environmental Hydraulics Institute at the University of Cantabria (Gómez-Martin and Medina 2008) using long-crested waves covering Iribarren numbers in the range $2.0-3.4$. The tests indicate a slightly better stability of the Cubipods compared to cubes.

A new comparison using short-crested waves was made at the Hydraulics and Coastal Engineering Laboratory at Aalborg University, Denmark (Burcharth et al. 2009).

The stability of Cubipod armour was compared both to earlier model tests with cubes (2004) and new tests with cubes (2009). In all cases were used identical roundhead geometry and test setup in the wave basin.

\footnotetext{
${ }_{2}^{1}$ Dept. of Civil Engineering, Aalborg University, Sohngaardsholmsvej 57, DK-9000 Aalborg, Denmark

${ }^{2}$ Universidad Politécnica de Valencia, ETSI Caminos, Camino de Vera s/n, 46022 Valencia, Spain 
ROUNDHEAD GEOMETRY AND ARMOUR MATERIALS

Figures 2 and 3 show the model cross section of the roundhead and the adjacent trunk.

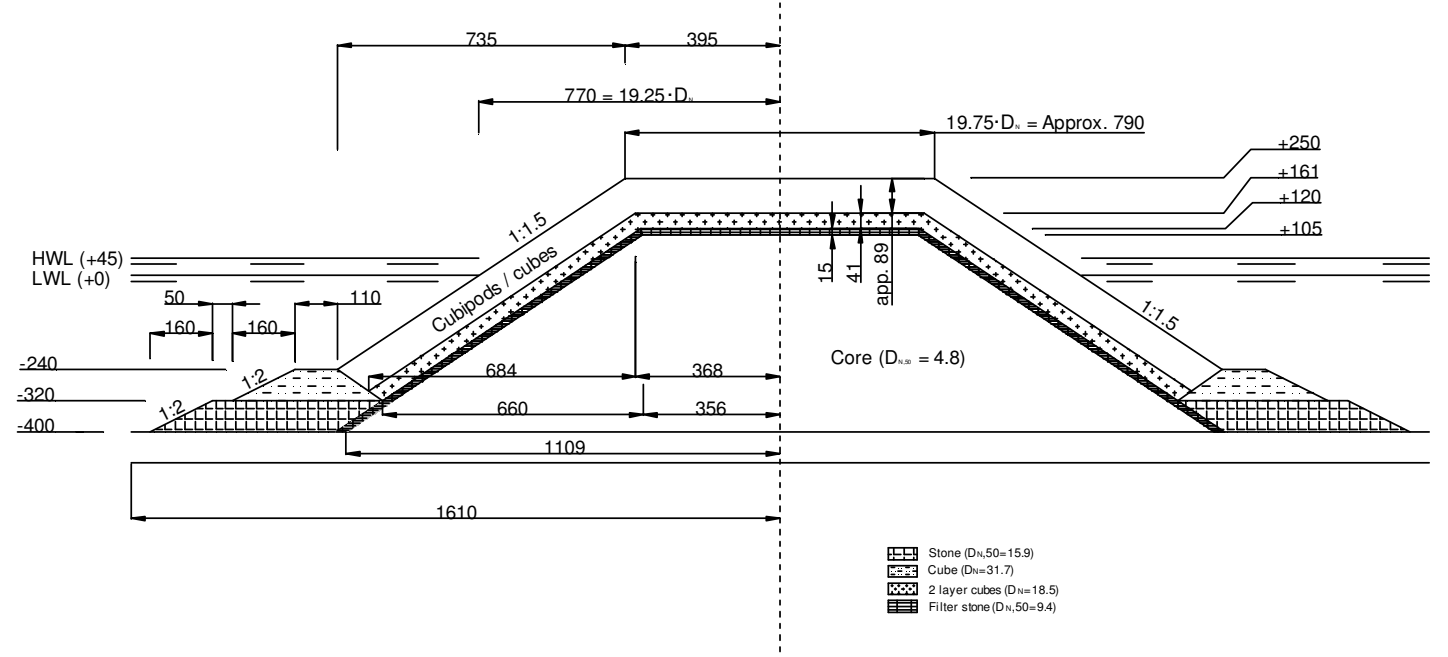

Figure 2. Model cross section of the roundhead (measures in $\mathrm{mm}$ ).

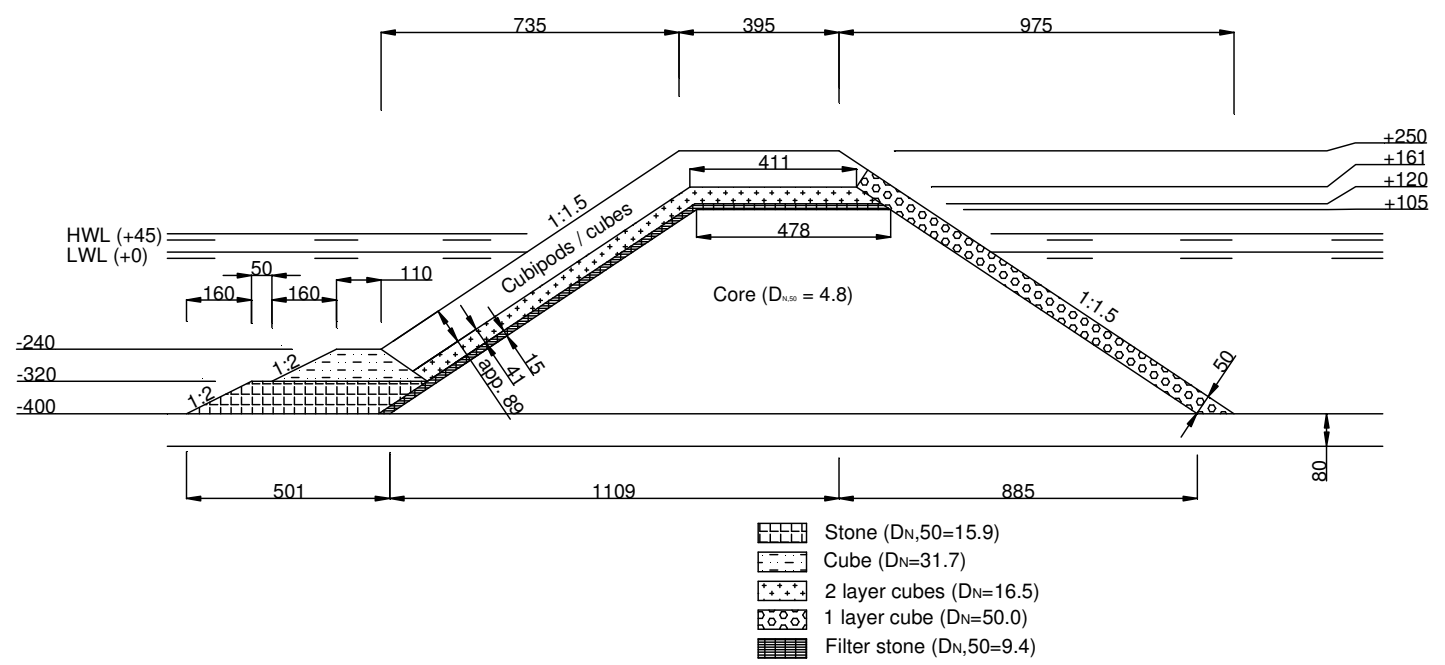

Figure 3. Model cross section of the trunk (measures in $\mathrm{mm}$ ).

The specifications of the materials applied in the models are given in Table 1.

\begin{tabular}{|l|c|c|c|c|}
\hline \multicolumn{6}{|l|}{ Table 1. Elements used for the model (model scale values). } \\
\hline Elements & $\begin{array}{c}\text { Block size } \\
{[\mathrm{mm}]}\end{array}$ & $\begin{array}{c}\text { Mass density } \\
{\left[\mathrm{t} / \mathrm{m}^{3}\right]}\end{array}$ & $\begin{array}{c}\text { Mass } \\
{[\mathrm{g}]}\end{array}$ & $\begin{array}{c}\Delta D_{\mathrm{n}} \\
{[\mathrm{m}]}\end{array}$ \\
\hline Armour cubes & $40 \times 40 \times 40$ & 2.32 & 146 & 0.053 \\
Cubipods & $\begin{array}{l}35 \times 35 \times 35 \text { (smallest dimension) } \\
\text { Toe parallellepipedes }\end{array}$ & 2.22 & 128 & 0.047 \\
Filter cubes - type 1 & $29 \times 29 \times 52$ (largest dimension) & 2.17 & 69 & 0.037 \\
Filter cubes - type 2 & $18.5 \times 18.5 \times 18.5$ & 2.34 & 15 & - \\
\hline
\end{tabular}

The core material was narrow graded crushed stones with $D_{\mathrm{n} 50}=4.8 \mathrm{~mm}$. The Cubipods and the cubes were randomly placed in a double layer. The thickness of the layers was approx. $89 \mathrm{~mm}$. corresponding to approx. 2.2 $D_{\mathrm{n}}$. Exact thickness cannot be given without a detailed definition of the surface of the armour layers. However, such definitions must be linked to the method of the measuring the surface.

The packing density and the related volume of concrete per unit area varied in the various models as given in Table 2. The area used in the calculation is that of the armour layer surface when taking layer thickness as $2.2 D_{\mathrm{n}}$. 


\begin{tabular}{|l|c|c|}
\hline \multicolumn{3}{|l|}{ Table 2. Packing densities and concrete volumes. } \\
\hline Tests & $\begin{array}{c}\text { Packing density } \\
{\left[\text { units } / D_{\mathrm{n}}{ }^{2}\right]}\end{array}$ & $\begin{array}{c}\text { Concrete volume } \\
{\left[\mathrm{m}^{3} / \mathrm{m}^{2}\right]}\end{array}$ \\
\hline Cubipods $(2009)$ & $1.23-1.24$ & $0.0445-0.0449$ \\
Cubes $(2009)$ & 1.27 & 0.0474 \\
Cubes $(2004)$ & 1.41 & 0.0525 \\
\hline
\end{tabular}

It is seen that approx. 6-17\% more concrete were used in the cube armour layer compared to the Cubipod armour layer.

\section{MODEL LAYOUT}

The layout of the model is shown in Fig. 4. The wave generators consist of 25 hydraulic operated snake type flaps with strokes (translation) up to $1.2 \mathrm{~m}$.

An array of seven wave gauges was used to record the directional waves. A three gauge array (always orientation in mean direction) was used as check on results from the seven gauge array.

A seabed slope of 1:25 was established on front of the breakwater model.
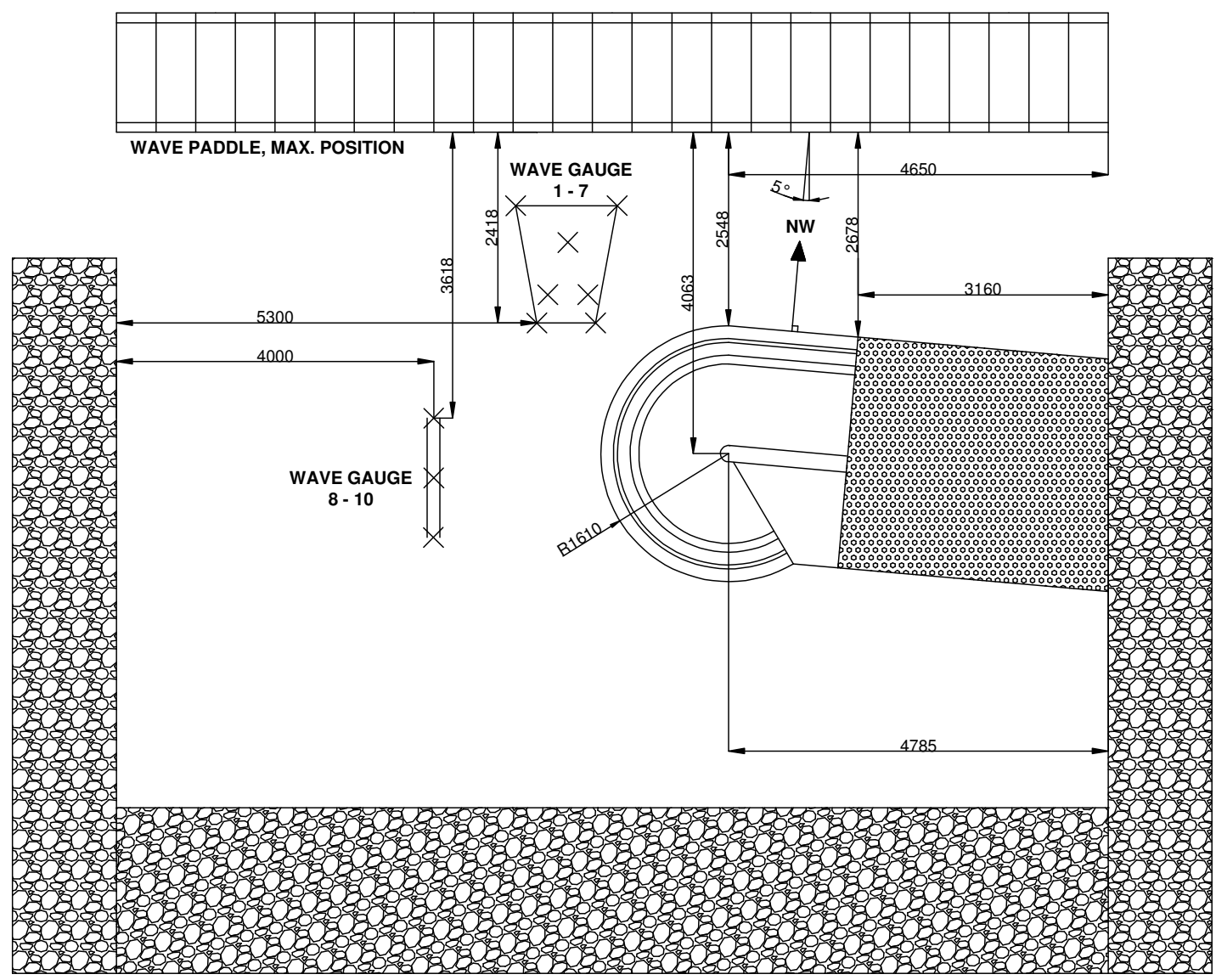

Figure 4. Layout of the model. Measures in $\mathrm{mm}$.

\section{WAVES AND WAVE ANALYSIS}

Both short-crested and long-crested waves were generated corresponding to a JONSWAP spectrum with peak enhancement parameter $\gamma=3.3$. For the short-crested waves was used the Longuet-Higgins spreading function with $s=15$. The waves were generated online by the AwaSys Program (Aalborg University 2008a). The incident wave spectra were analyzed using WaveLab (Aalborg University 2008b). This software package uses the BDM-method (Hashimoto and Kobune 1988) for directional wave analysis.

An example of the 3D variance spectrum is shown in Fig. 5. 


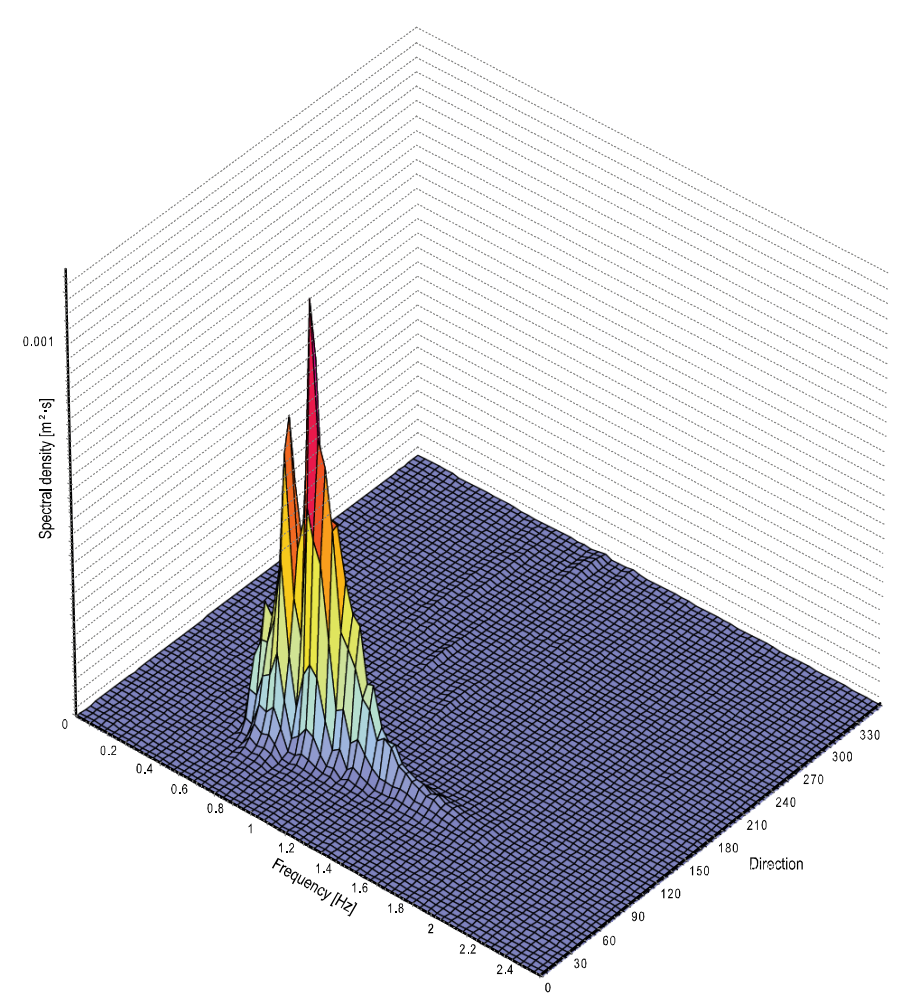

Figure 5. Example of variance spectrum.

Wave steepness were in the range $s_{0 \mathrm{p}}=0.02-0.05$. The Iribarren number range was $I_{r}=\frac{\tan \alpha}{\sqrt{\frac{H_{s}}{s_{o p}}}}=3.0-4.4$. The maximum stability number reached among all tests was $N_{s}=\frac{H_{s}}{\Delta D_{n}}=3.4$. The Reynolds number $\operatorname{Re}=\frac{\sqrt{g H_{s}} \cdot D_{n}}{v}$ was approx. $5 \cdot 10^{4}$, sufficient to avoid scale effects related to armour stability. $v$ is the kinematic viscosity.

Two mean wave directions were used in the tests: Angle of incidence $0^{\circ}$ and $22.5^{\circ}$, cf. Fig. 6 .

\section{DAMAGE DEFINITION AND OBSERVATION}

The roundhead was divided into sectors as shown in Fig. 6 in order to facilitate determination of the spatial distribution of damage. Note that the sectors are not identical in the tests with Cubipods and cubes. The damage is given for each sector and for the whole roundhead $\left(180^{\circ}\right.$ sector) as percentage of units displaced more than one $D_{\mathrm{n}}$.

Sectors for tests with Cubipods (2009)

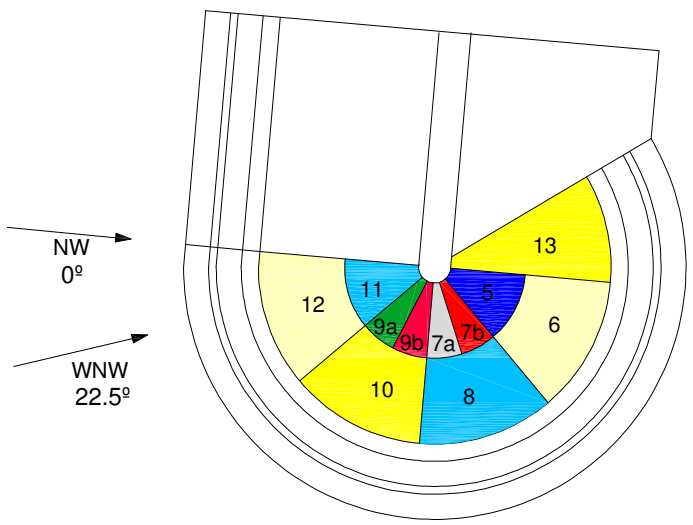

Sectors for tests with cubes (2004 and 2009)

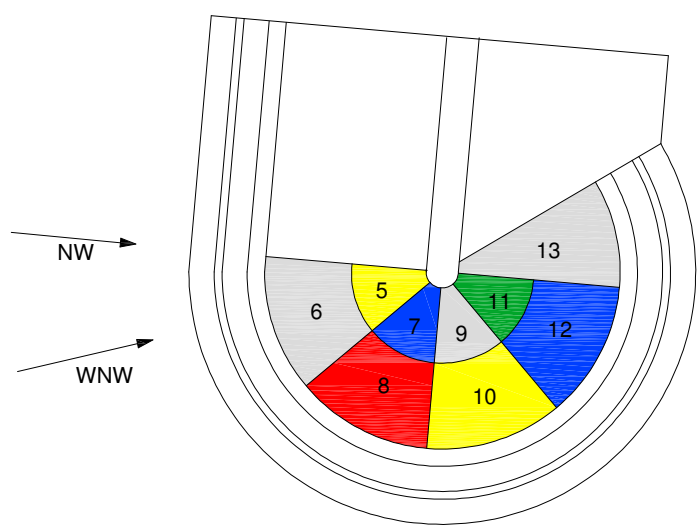

Figure 6. Division of roundheads into sectors. 


\section{TEST RESULTS}

Typical examples of test results are given below.

\section{2-D Waves}

Fig. $7 \mathrm{a}, 7 \mathrm{~b}$ and $7 \mathrm{c}$ show the damage development in tests with 2-D waves, $s_{0 \mathrm{p}}=$ approx. 0.04 and angle of incidence $0^{\circ}$.

a)

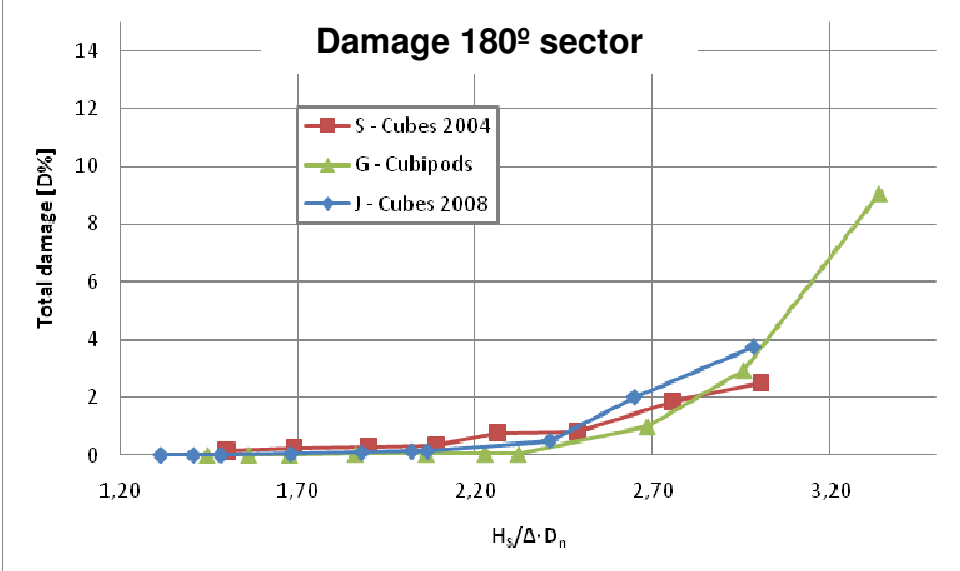

b)

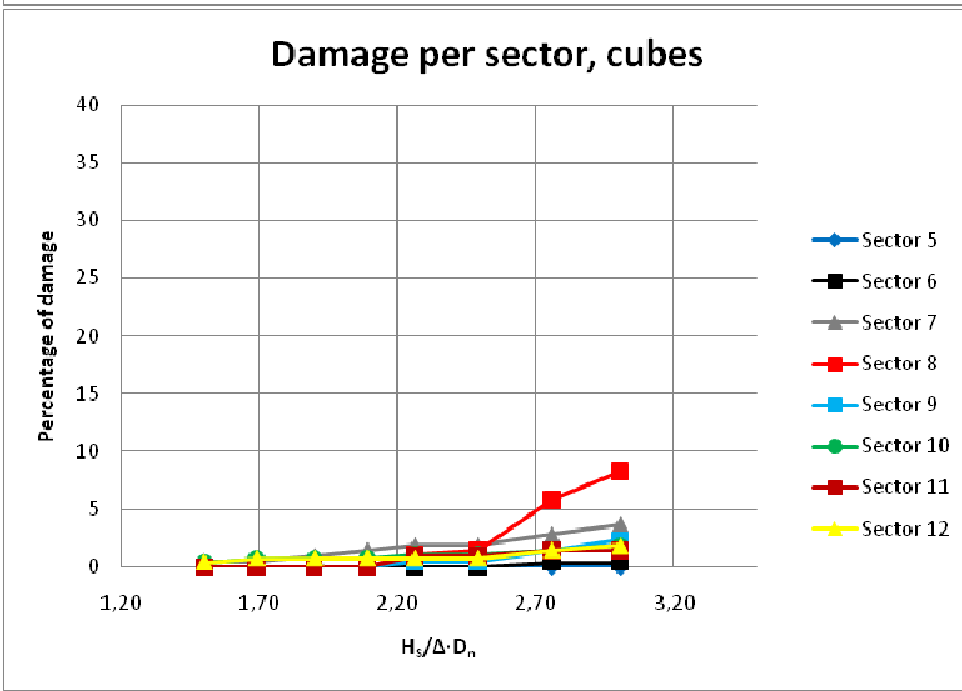

c)

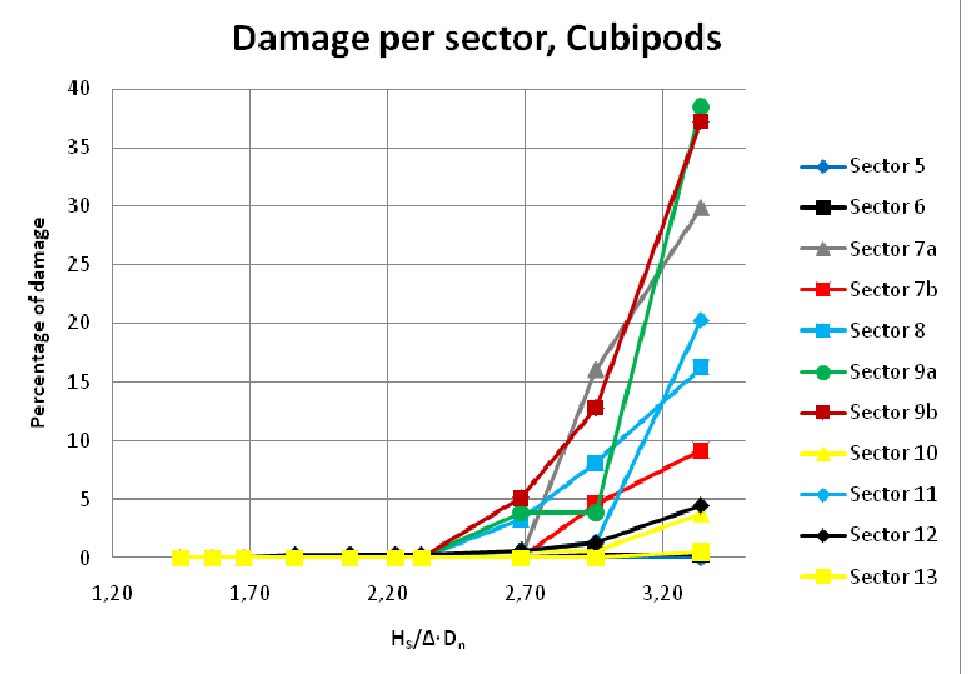

Figure 7. Damage in tests with 2-D waves $s_{0 p}=$ approx. 0.04 and angle of incidence $0^{\circ}$. 
It is seen that the total damages in a $180^{\circ}$ sector is almost the same for Cubipods and cubes. The dispersion of damage over the roundhead is however more pronounces for the Cubipod armour (the larger number of sectors taken into account).

Fig. $8 \mathrm{a}$ and $8 \mathrm{~b}$ show photos of the end of the tests presented in Fig. 7.

a)

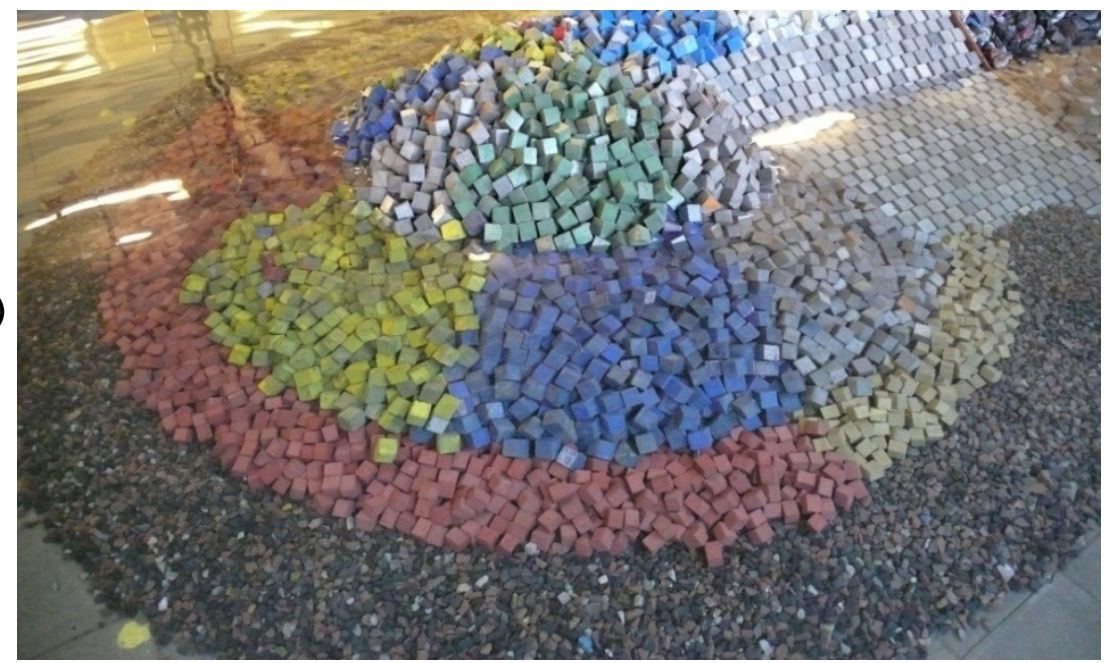

b)

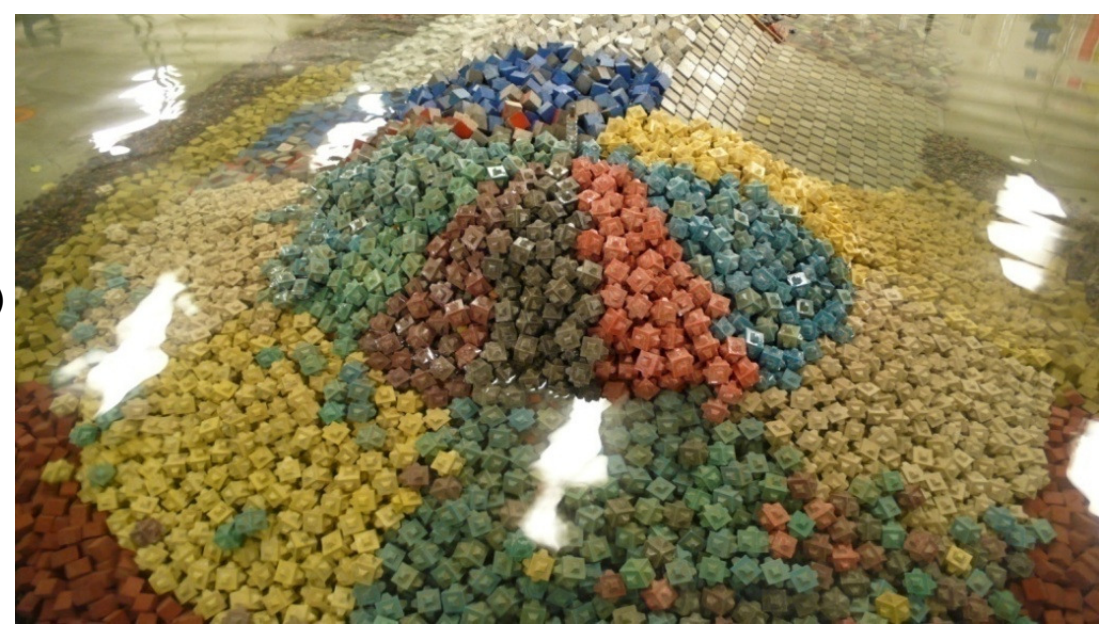

Figure 8. Photos of the roundheads after exposure to 2-D waves $s_{0 p}=$ approx. 0.04 and angle of incidence 0 . a) Cube armour, $N_{s}=2.98, H_{s}=15.69 \mathrm{~m}$ at scale 1:100. b) Cubipod armour, $N_{s}=3.34, H_{s}=15.67$ at scale $1: 100$. 


\section{3-D Waves}

Fig. 9a, 9b and 9c show damage in the tests with 3-D waves, $s_{0 \mathrm{p}}=$ approx. 0.035 and angle of incidence $0^{\circ}$.

a)

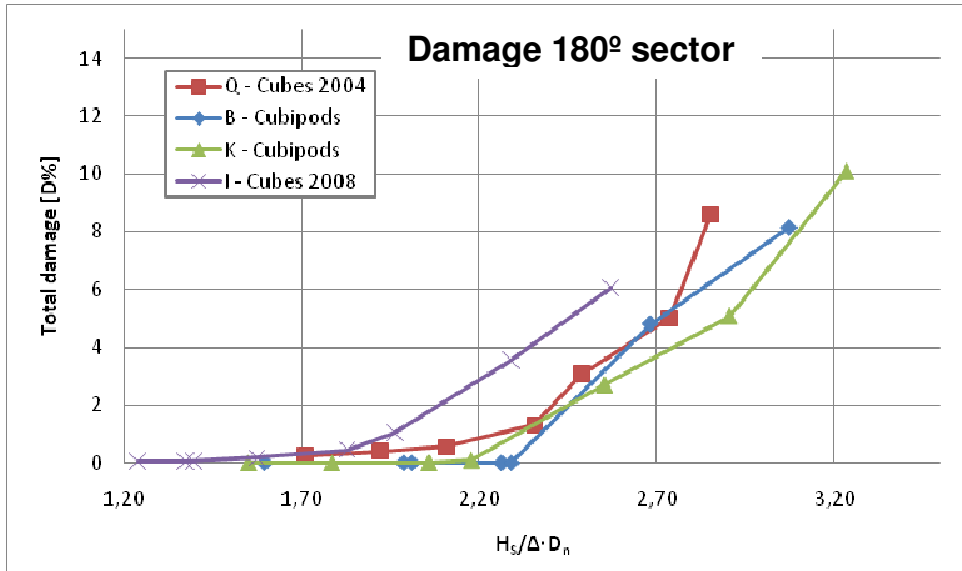

b)

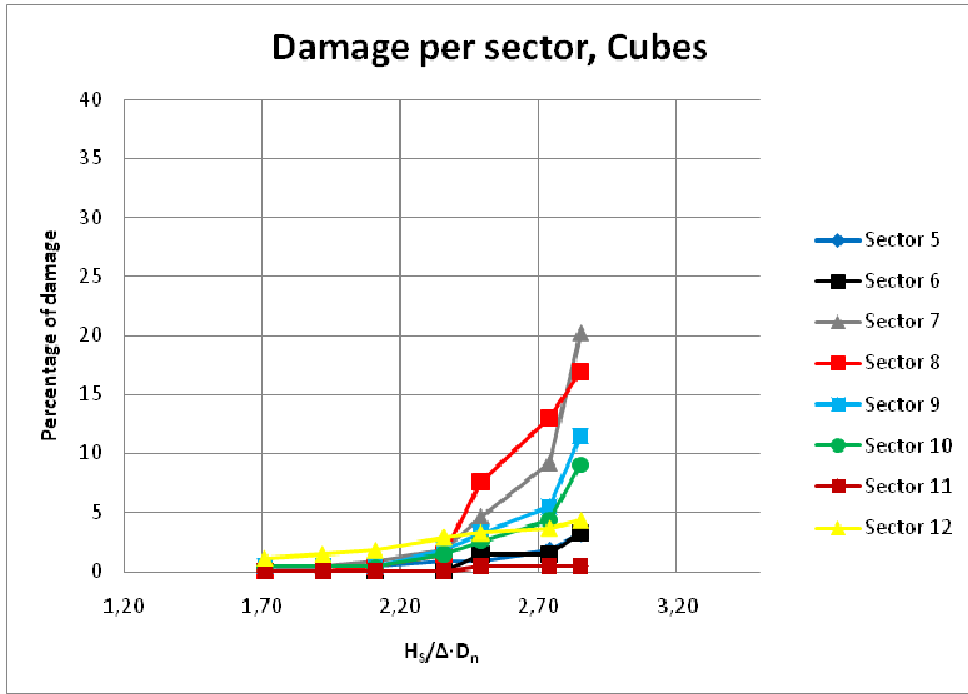

c)

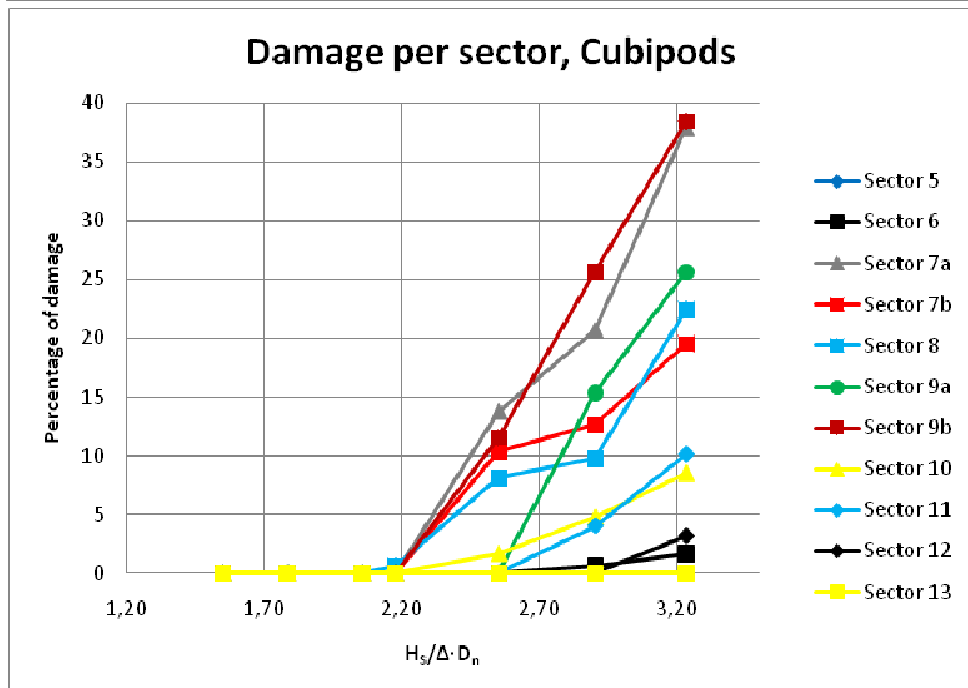

Figure 9. Damage in test with 3-D waves $s_{0 p}=$ approx. 0.035 and angle of incidence $0^{\circ}$.

It is seen that Cubipod armour perform better than cube armour. Fig. 10 shows as an example a photo of the maximum observed damage of Cubipod armour after exposure to waves reaching $N_{\mathrm{s}}=3.2$. Only at two locations are the filter layer visible over limited areas. 


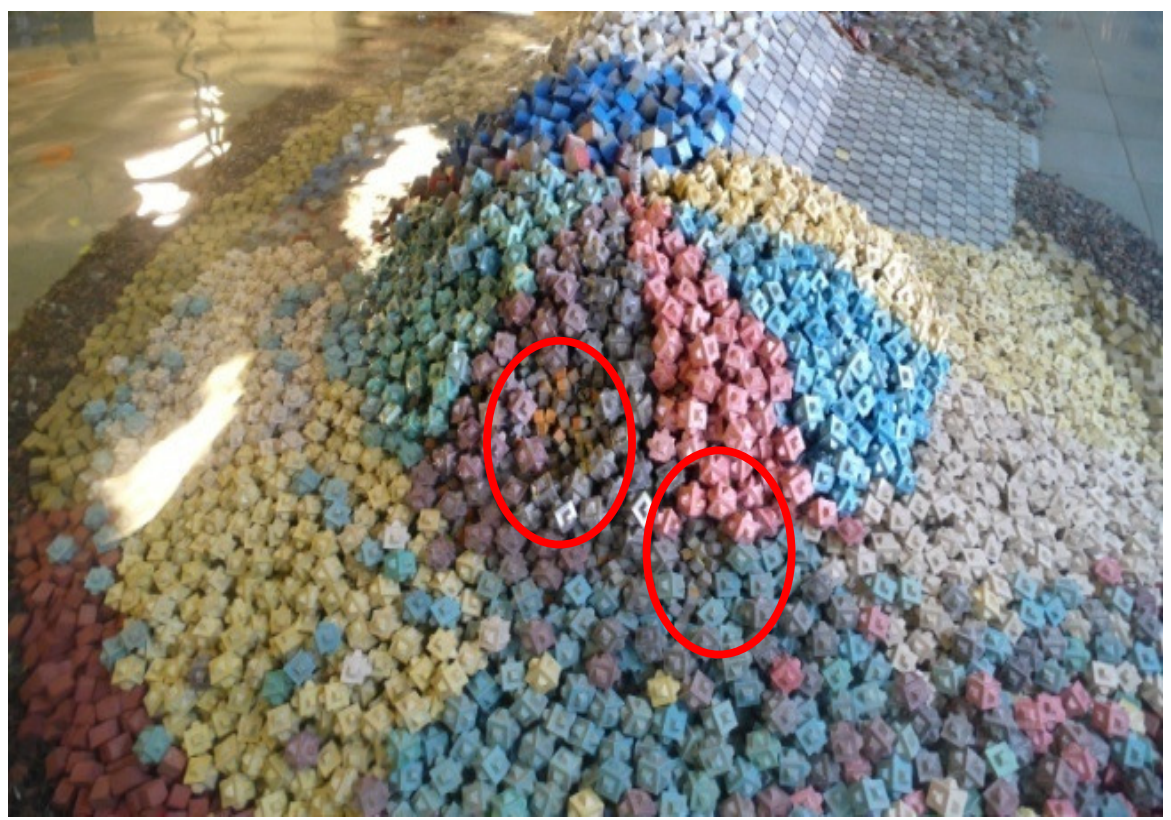

Figure 10. Exposed filter in Cubipod for $N_{s}=3.2 .3-D$ waves, $s_{0 p}=$ approx. 0.035 and angle of incidence $0^{\circ}$.

Fig. 11a and $11 \mathrm{~b}$ show damages in Cubipod and cube armour layers over $180^{\circ}$ sectors for angle of incidence $0^{\circ}$ and $22.5^{\circ}$, respectively.

a)
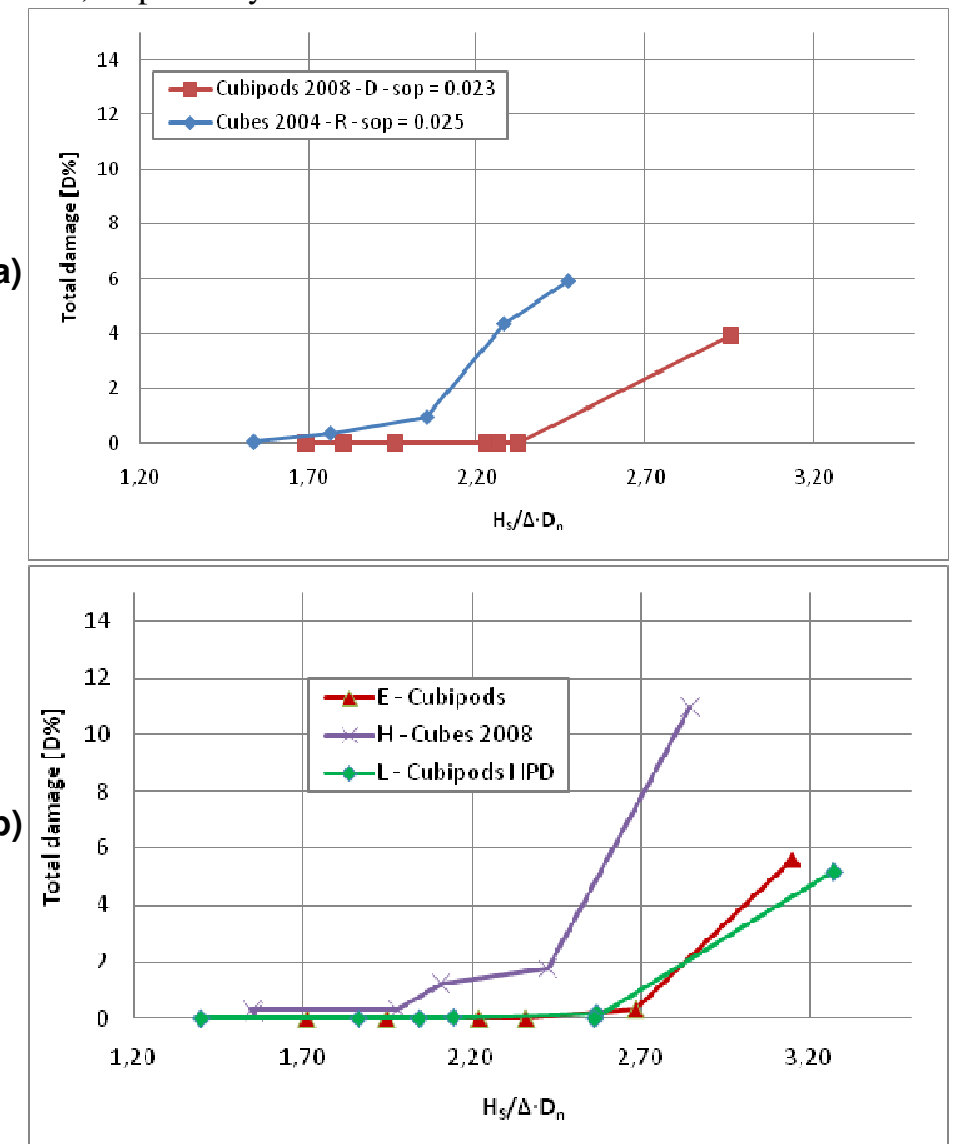

Figure 11. Accumulated damage over $180^{\circ}$ sector. 3-D waves $s_{0 \mathrm{p}}=$ approx. 0.025 . a) Angle of incidence $0^{\circ}$. b) Angle of incidence $22.5^{\circ}$. 
It is seen from Fig. 11 that in the waves of small steepness, the Cubipod armour is significantly more stable than the cube armour.

The differences in damage between the two types of armour is clearly seen in Figs. 12a and 12b which shows photos of the armour at the end of the test series with 3-D waves, $s_{0 \mathrm{p}}=$ approx. 0.025 and angle of incidence $22.5^{\circ}$. Note that for the cubes, the reached $N_{\mathrm{s}}=2.85$, whereas for the Cubipods $N_{\mathrm{s}}=$ 3.15 .

a)

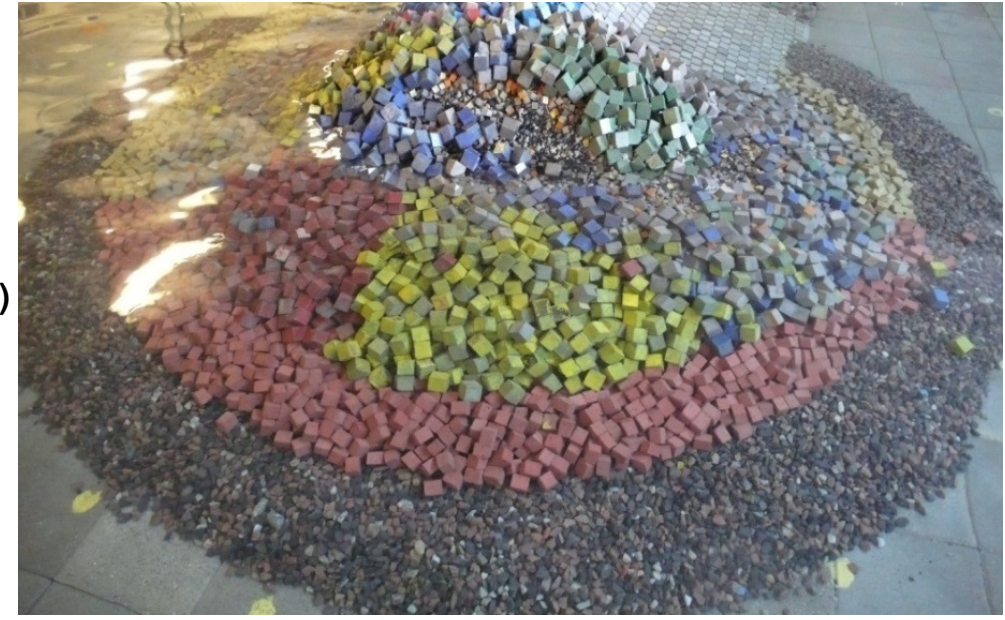

b)

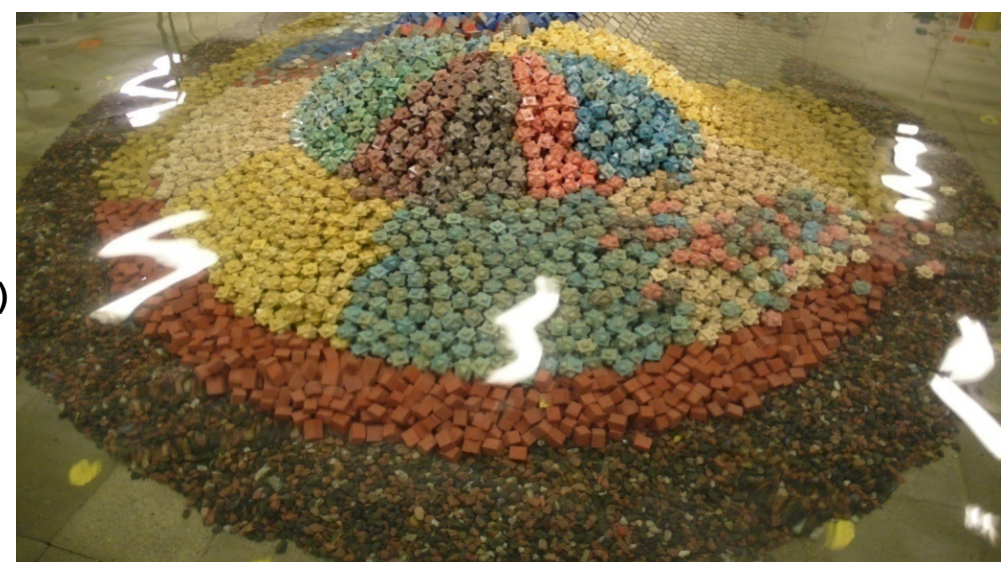

Figure 12. Photos of armour damage at the end of tests with 3-D waves, $s_{0 p}=$ approx. 0.025 and angle of incidence $22.5^{\circ}$. a) cube armour, $N_{s}=2.85, H_{s}=14.97$ at scale 1:100. b) Cubipod armour, $N_{s}=3.15, H_{s}=14.79$ at scale 1:100.

\section{CONCLUSIONS}

The following conclusions are limited to comparative tests with only one roundhead geometry, i.e. slope 1:1.5 and a fairly large diameter. Moreover, the waves were non-depth limited. The conclusions extracted from the tests (not all presented in this paper) are as follows:

- In 2-D steep waves $\left(s_{0 \mathrm{p}}=0.05\right)$ : No significant difference in cube and Cubipod stability.

- In 3-D medium steep waves $\left(s_{0 \mathrm{p}}=0.035\right)$ : Cubipods might be marginally more stable than cubes.

- In 3-D long waves $\left(s_{0 \mathrm{p}}=0.025\right)$ : Cubipods are significantly more stable than cubes.

- The stability of both cube and Cubipod armour is reduced in 3-D waves compared to 2-D waves.

- Cubipod armour seems to have reduced stability in steeper waves.

- Cubipod armour stability seems not affected by small changes in laying density in the range 1.241.30 units $/ D_{\mathrm{n}}{ }^{2}$.

In evaluating these conclusions it should be considered that the volume of concrete used in the cube armour layers were 6\% - 17\% larger than in the Cubipod armour layer. The larger porosity of Cubipod armour is most probably the reason for the better performance of Cubipod armour in long waves. The roundhead stability formula for cubes (Macineria and Burcharth, 2007) can be modified to include Cubipod armour as shown in Gómez-Martin and Medina, 2008. 


\section{ACKNOWLEDGMENTS}

MSc Jose Maria Urrutia Aldama is acknowledged for his work with the model testing.

\section{REFERENCES}

Aalborg University 2008a. AwaSys 5 - Wave Generation and Active Absorption Software. http://hydrosoft.civil.aau.dk/AwaSys. Dept. of Civil Engineering, Aalborg University.

Aalborg University 2008b. WaveLab2 - Data Acquisition and Analysis Software for Wave Laboratories. http://hydrosoft.civil.aau.dk/wavelab. Dept. of Civil Engineering, Aalborg University.

Burcharth, H.F., Lykke Andersen, T. and Urrutia Aldama, J.M. 2009. Three-Dimensional Model Tests Study of a Cubipod Armoured Roundhead. DCE Contract Report No 58. Division of water and Soil, Department of Civil Engineering, Aalborg University, Denmark.

Gómez-Martin, M.E. and Medina, J.R. 2008. Erosion of Cubipod armour layers under wave attack. Proc. 31 st International Conference on Coastal Eng., ASCE, 3461-3473.

Hashimoto, N. and Kobune, K. 1988. Estimation of directional spectrum from a Bayesian approach. Proc. 21st International Conference on Coastal Eng., ASCE, 62-72.

Macineira, E. and Burcharth, H.F. 2007. New formula for stability of cube armoured roundheads. Proc. $5^{\text {th }}$ Coastal Structures 2007 International Conference, World Scientific, 31-40. 